PENENTUAN NASABAH PENERIMA REWARD PRODUK GOLD DENGAN METODE SIMPLE ADDITIVE WEIGHTING (SAW) STUDI KASUS : PT. PINJAM INDONESIA

Riki Ruli A. Siregar; Faizal Fachrurrozi

IMPLEMENTASI METODE BACKWARD CHAINING PADA DATA WAREHOUSE DAOP 1 JAKARTA PT. KAI (PERSERO) Rakhmat Arianto; Chandra Bagus Sugiarto

IMPLEMENTASI METODE DETEKSI TEPI CANNY PADA OBJEK SEBAGAI MODEL KEAMANAN APLIKASI PADA SMARTPHONE ANDROID

Abdul Haris; Andi Prasetyo

ANALISA DATA DAN PERANCANGAN APLIKASI SERVICE PELANGGAN PT. JNE UNTUK PENINGKATAN KUALITAS LAYANAN

Dewi Arianti Wulandari; Sonny Syahrindra Putra

JARINGAN AD-HOC VEHICULAR (VANET) : TINJAUAN TENTANG ARSITEKTUR, KARAKTERISTIK, APLIKASI, DAN PROTOKOL MEDIUMACCESS CONTROL (MAC)

Rosida Nur Aziza

PERANCANGAN APLIKASI PENJADWALAN MATA KULIAH MENGGUNAKAN METODE CONSTRAINT PROGRAMMING Syam Gunawan

RANCANGAN TATA KELOLA PEREMAJAAN RUANG KELAS DIREKTORAT PEMBINAAN SEKOLAH DASAR

Ratna Mutu Manikam; Purwanto

PENGEMBANGAN AMORIK MENGGUNAKAN METODE GARIS SINGGUNG TERHADAP DUA LINGKARAN DAN PERSAMAAN KURVA BEZIER ORDE DUA.

Darma Rusjidi

OPTIMALISASI PENGAMBILAN KEPUTUSAN PENILAIAN KINERJA DOSEN PADA PERGURUAN TINGGI ISLAM XYZ MENGGUNAKAN AHP (ANALYTICAL HIERARCHY PROCESS)

Rahma Farah Ningrum

PENGAMANAN SMS PADA TELEPON SELULER BERBASIS ANDROID MENGGUNAKAN ALGORITMA TRIPLE DES Raka Yusuf; $M$. Rival Suheri

APLIKASI LATIHAN SOAL UJIAN TEORI SURAT IZIN MENGEMUDI BERBASIS WEB Harni Kusniyati; Raka Yusuf; Andri Setiawan

RANCANG BANGUN SIMULASI TERJADINYA LISTRIK DENGAN SUMBER DAYA SAMPAH BERBASIS MULTIMEDIA (STUDI KASUS : TPST BANTAR GEBANG)

Yasni Djamain; Ika Fitriyani Putri

\begin{tabular}{|c|c|c|c|c|c|c|}
\hline \multirow{2}{*}{ 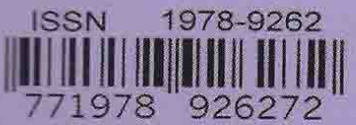 } & \multicolumn{6}{|c|}{ SEKOLAH TINGGI TEKNIK - PLN (STT-PLN) } \\
\hline & PETIR & VOL. 9 & No. 1 & HAL. 1 - 87 & JAKARTA, MARET 2016 & ISSN $1978-9262$ \\
\hline
\end{tabular}




\title{
PENGEMBANGAN AMORIK MENGGUNAKAN METODE GARIS SINGGUNG TERHADAP DUA LINGKARAN DAN PERSAMAAN KURVA BEZIER ORDE DUA
}

\author{
Darma Rusjdi \\ Program Studi Teknik Informatika Sekolah Tinggi Teknik PLN Jakarta \\ drusjdi@yahoo.com
}

\begin{abstract}
ABSTRAK
Penerapan pemodelan obyek rangka berupa garis lurus dan lingkaran serta pembuatan gambar antara melalui persamaan garis lurus pada aplikasi Amorik 2.0 perlu dikembangkan agar lebih menggambarkan model berbentuk dua dimensi dan menghasilkan gerakkan melengkung yang lebih baik. Metodologi daur hidup dengan tiga putaran perbaikan (siklus), diawali melalui studi pustaka pengembangan model obyek rangka menggunakan metode dua garis singgung pada dua lingkaran dan pembuatan gambar-gambar antara menggunakan persamaan Kurva Bezier orde dua. Pengembangan aplikasi sederhana untuk pemodelan dan pembuatan gerakkan animasi secara vektor dan pengujian melalui observasi penggunaan aplikasi diimplementasikan didalam empat kelas laboratorium dengan pengguna masing-masing kelas 30 orang tingkat mahasiswa, siswa SMA, dan siswa SMP. Berdasarkan hasil ujicoba didapatkan hasil berupa pemodelan obyek rangka dua dimensi berupa model orang yang dapat menghasilkan gambar kunci (keyframe) lebih luwes dan aplikasi dapat menghasilkan gerakan melengkung dari obyek dan komponen obyek lebih luwes.
\end{abstract}

Kata kunci: Metode Garis Singgung Dua Lingkaran, Interpolasi Kurva Bezier Orde Dua, Amorik3

\section{Pendahuluan}

Pembuatan aplikasi animasi komputer dilakukan karena adanya mata kuliah Teknik Animasi yang lebih spesifik sebagai pengganti mata kuliah Grafika Komputer yang bersifat umum. Pada mata kuliah ini memiliki dua sasaran strategis yaitu membelajarkan ketrampilan teknik membuat animasi secara berkelompok (manajemen pelaksanaan) dengan menggunakan program aplikasi komputer dan memberi pengetahuan dan kemampuan menerapkan konsep grafika komputer sebagai dasar teori pembuatan program aplikasi komputer.

Pembuatan aplikasi animasi model obyek rangka dengan konsep inbetweening keyframe disingkat Amorik sampai versi 2.0 (terdaftar dalam hak cipta HAKI) dapat digunakan untuk membuat animasi berbasis model obyek rangka garis (stick figure). Pembuatan keyframe model obyek rangka yang mudah dan menghasilkan gerakkan yang cukup halus melalui proses pembuatan gambar antara (inbetweening) dari dua gambar kunci (keyfarme).

Animasi yang dikembangkan dapat menunjukkan gerakkan tarian atau olahraga namun masih memiliki beberapa kendala. Kendala berupa model obyek rangka masih satu dimensi (stick figure) dan perubahan gerak animasi masih menggunakan interpolasi linier dari persamaan garis lurus sehingga gerakkan masih terlihat kaku. Agar menghasilkan gerakkan yang lebih luwes dan efisien perlu menyisipkan gambar kunci yang lebih banyak. Oleh karena itu untuk pengembangan aplikasinya diperlukan pengembangan model obyek rangka dua dimensi dan menghasilkan gerakan yang lebih luwes.
Berdasarkan implementasi model rangka garis yang dibuat sebagai penghubung dua titik yang menjadi sendi dari garis bisa menjadi acuan pengembangan. Agar dapat dikembangkan menjadi bentuk bidang, maka titik sendi dibuat berjarak berupa radius lingkaran. Dan jika dihubungkan dengan dua garis penghubung (garis singgung lingkaran), akan terlihat sebagai bidang. Dan untuk menghasilkan gerakkan yang lebih luwes dibutuhkan minimal persamaan garis yang melalui tigaris yang melalui tiga buah titik. Hal penting lainnya adalah perlu mengembangkan antarmuka pemakai yang baik.

Rumusan Masalah diuraikan sebagai berikut:

Pertama, bagaimana mengembangkan model obyek rangka dua dimensi yang mengembangkan model obyek rangka dua dimensi yang luwes melalui metode dua garis singgung pada dua lingkaran?

Kedua, bagaimana membuat gambar-gambar antara yang dapat menghasilkan gerakkan melengkung lebih sederhana dan luwes melalui persamaan interpolasi kurva bezier orde dua serta memudahkan dalam pengaturan gambar kunci (keyframe)?

Dan ketiga, bagaimana membuat antarmuka pemakai yang memudahkan pembuatan gerakan animasi yang baik?

Tujuan kajian adalah agar pengembangan aplikasi Amorik dapat menerapkan konsep pembuatan model obyek rangka dua dimensi dan dapat menghasilkan gerakkan melengkung lebih baik serta menghasilkan antarmuka yang dapat memudahkan penggunaan aplikasi.

Manfaat bagi pengguna yaitu dapat membuat model lebih mudah dibentuk, dengan gerakkan 
lebih halus, luwes, dan dapat digabungkan dengan frame latar atau frame model lain serta dapat dijadikan bahan baku pembuatan video animasi melalui aplikasi pembuatan video.

\section{Landasan Teoretik}

\subsection{Animasi Komputer}

Animasi (Zeid, 2005) merupakan ilusi bergerak secara visual dari perubahan gambargambar yang ditampilkan secara berurutan. Animasi komputer yang dibuat atau ditampilkan menggunakan aplikasi komputer. Spektrum pembuatan animasi dari pendekatan konvensional ke penggunaan komputer murni (total). Pendekatan konvensional menggunakan media grafik non komputer seperti pena dan kertas serta kamera setelah itu penyelesaian dengan aplikasi grafika komputer.

Pada pendekatan konvensional, pembuatan gambar-gambar (frame) menggunakan gambar kunci (keyframe) agar dapat dikembangkan gambar-gambar antara (inbetweening) sehingga menghasilkan ilusi gerak yang halus.

Penggambaran setiap frame membutuhkan ketrampilan pembuatan perubahan karakter obyek dan latar gambar secara baik yang membutuhkan waktu pembuatan yang cukup lama termasuk pewarnaan. Pembuatan animasi secara bersama (tim pembuatan animasi) menjadi solusi untuk mengatasi durasi waktu pembuatan yang terbatas.

Model animasi komputer dapat berbentuk dua dimensi seperti pembuatan gambar diatas kertas dengan model bidang atau terlihat tiga dimensi. Bentuk tiga dimensi dapat berupa obyek bidang maupun obyek padat (solid) yang dapat diproyeksikan secara paralel atau perspektif dari berbagai jarak dan sudut pandang (transformasi pandangan). Model dua dan tiga dimensi dapat dilakukan transformasi obyek (Krishnamurthy, 2002) atau perubahan posisi elemen obyek dengan metode geser $(x+n, y+m)$, putar $(x 0+r \cdot \cos (a), \quad y 0+r \cdot \sin (a)), \quad$ skalatis $(x n, y n$ atau $\mathrm{xn}, \mathrm{ym})$.

\subsection{Aplikasi Amorik}

Program Komputer Amorik singkatan dari Animasi Model Obyek Rangka Inbetweening Keyframe versi 3.0 Sketsa Karakter 2 Dimensi dibuat dan dikembangkan sejak bulan September sampai dengan bulan Desember 2014. Pada bulan Februari 2015 dilakukan perbaikan sebelum implementasi dan sesudah implementasi oleh siswa SMA dan SMP pada kegiatan Pengabdian Kepada Masyarakat.

Program Amorik3 adalah perangkat lunak aplikasi animasi yang didisain sebagai pengembangan karakter dua dimensi dari program sebelumnya yaitu amorik2 berupa rintisan awal model obyek rangka dengan karakter satu dimensi atau karakter obyek batang atau garis lurus.

Tujuan pengembangan program perangkat lunak aplikasi ini sebagai implementasi konsep komputer grafik untuk menghasilkan gambargambar karakter obyek 2D yang dapat menghasilkan ilusi gerakkan yang halus melalui proses pembuatan dengan interaksi yang lebih mudah dan produktif.

Manfaat bagi pengguna awal dimana pembuatan animasi dapat dilakukan secara perorangan maupun berkelompok untuk menyelesaikan tahapan pembuatan sketsa karakter animasi dengan perubahan gerak secara halus dan produktif.

Metode yang digunakan dalam penggambaran grafik berbasis dua lingkaran yang dihubungkan oleh dua garis singgung secara simetris. Sejumlah gerakkan (inbetweening keyframe) dengan perbedaan posisi koordinat secara halus dibuat menggunakan lintasan persamaan garis dengan metode bezier kuadratik dari 2 titik koordinat yaitu titik awal dan titik akhir serta titik koordinat ketiga sebagai acuan tengah.

Ketiga titik koordinat tersebut diatas mewakili obyek dari 2 frame kunci yaitu awal dan akhir serta frame kunci ketiga sebagai acuan tengah. Ketiga frame kunci sebagai acuan untuk mendapatkan titik bantu bagi persamaan (algoritma) tersebut.

Aplikasi ini menghasilkan file yang berisi sejumlah gerakan berupa data koordinat $x, y$ dan radius lingkaran serta kumpulan file citra bmp dari sejumlah gerakkan yang berada pada direktori FRAME.

\subsection{Model Obyek Rangka}

Tiga model obyek grafik (Gesner,1992; Zeid,2005) yaitu: bentuk rangka (wire frame), bentuk bidang (surface), dan bentuk padat (solid). Pembahasan menggunakan bentuk rangka dasar dasar berupa obyek garis lurus dan garis lengkung (algoritma bresenham) serta bentuk lain berupa lingkaran dan elips.

Persamaan garis lurus (Xiang,2001, h.26):

$F(x)=m \cdot x+b$

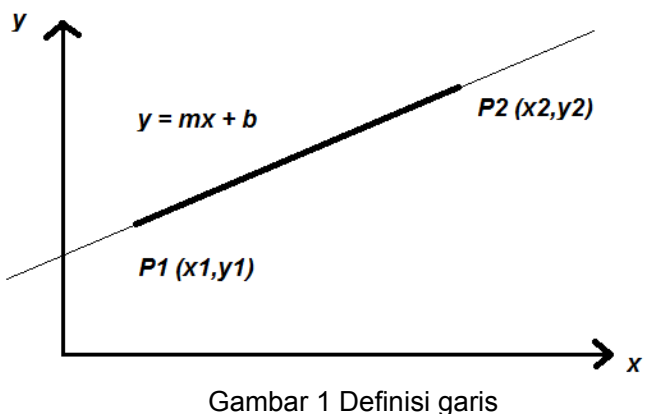

Dimana:

$m=(y 2-y 1) /(x 2-x 1)$

$\mathrm{b}=\mathrm{y} 1-\mathrm{mx}$

Pendekatan penggambaran titik-titik membentuk garis disebut konversi scan. konversi scan sederhana menggunakan persamaan menggunakan persamaan garis. Jika $|\mathrm{m}| \leq 1$, untuk setiap nilai $x$ antara $x 1$ da $x 2$ perhitungan nilai $y$ menggunakan persamaan yang ada dan konversi scan. Jika $|m|>1$, untuk setiap nilai y antara y1 dan y2 perhitungan nilai $x$ secara koresponden menggunakan persamaan yang ada dan konversi scan. Pendekatan yang lebPendekatan yang lebih 
cepat penghitungan dibanding menggunakan persamaan garis yaitu dengan algoritma DDA (digital differential analyzer) da Algoritma garis Bresenham.

Konversi scan untuk membentuk lingkaran dapat melalui persamaan lingkaran yaitu persamaan polinomial orde kedua,

$$
P=\left(x, \operatorname{SQR}\left(r^{2}-x^{2}\right)\right.
$$

metode kedua dengan menggunakan fungsi trigonometri dimana:

$$
\begin{aligned}
& x=x_{0}+r \cos \alpha \\
& d a n y=y_{0}+r \sin \alpha
\end{aligned}
$$

metode ketiga dapat menggunakan algoritma lingkaran Bresenham yang menggunakan hanya penambahan, pengurangan dan perkalian secara integer dengan perpangkatan dua.

\subsection{Metode Garis Singgung Dua Lingkaran}

Garis singgung lingkaran merupakan garis yang menyinggung suatu lingkaran tepat melalui satu titik pada garis lingkaran. Contoh persamaan garis singgung melalui titik $A(x, y)$ pada lingkaran yang memiliki persamaan $x^{2}+y^{2}=r^{2}$, yaitu lingkaran yang berpusat di titik $(0,0)$ dan berjari-jari

Pembentukan model obyek dari bentuk rangka dasar atau berbagai bentuk model rangka geometrik membutuhkan banyak prosedur fungsi. Untuk menyederhanakan didapatkan satu bentuk dasar model rangka berupa dua garis singgung pada dua lingkaran sebagai pengembangan dari model obyek rangka batang pada Amorik2.

Bentuk tersebut dapat dikembangkan menjadi berbagai bentuk geometri dimana titik lingkaran dapat digunakan sebagai titik pusat putar obyek dan diameter lingkaran dapat membentuk ukuran model.

Persamaan garis singgung dua lingkaran dibangun berdasarkan gambar Garis singgung dua lingkaran di bawah ini:

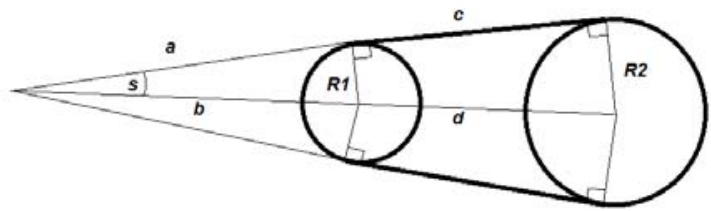

Gambar 2. Garis singgung dua lingkaran

Pada gambar terdapat dua lingkaran yang didefinisikan berdasarkan kebutuhan melalui titk pusat lingkaran satu $(x 1, y 1)$ dan titik pusat lingkaran dua $(x 2, y 2)$, dimana masing-masing dengan jari-jari R1 dan R2. Dari kedua pusat lingkaran didapatkan jarak d. Sebagai ilustrasi garis singgung $\mathrm{c}$ dapat digambarkan dari kedua lingkaran berjarak R1 dan R2 dalam keadaan siku terhadap arah R1 dan R2. Dalam keadaan tersebut R1 dan R2 sejajar. Jika garis c dan d bertemu disatu titik akan membentuk dua segitiga sebangun, dimana $\mathrm{R} 1<\mathrm{R} 2$ atau $\mathrm{R} 1>\mathrm{R} 2$. Jika $\mathrm{R} 1=\mathrm{R} 2$ membentuk persegi (panjang).

Perpanjangan $\mathrm{c}$ dan $\mathrm{d}$ ke titik pertemuan menghasilkan panjang a dan b serta membentuk sudut s. Sudut s dapat dicari berdasarkankan aturan bentuk segitiga siku yang terbentuk oleh garis $c$, d dan [R1-R2]. Jika [R1-R2] adalah panjang e maka c dan e membentuk siku dan sudut $\mathrm{s}$ dibentuk garis $\mathrm{c}$ dan $\mathrm{d}$. Sehingga arah R1 dan R2 adalah 90 -s atau $\mathrm{s}+90$ terhadap garis $\mathrm{d}$.

\subsection{Persamaan interpolasi Kurva Bezier Orde} Dua.

Gerakkan model obyek pada amorik2 menggunakan persamaan garis regresi linier menghasilkan gerakkan yang masih kaku, untuk menghaluskan gerakkan perlu menyisipkan keyframe yang lebih banyak. Untuk memperbaiki gerakkan menjadi lebih halus dibutuhkan interpolasi titik-titik berbentuk kurva (Chapra, 1990).

Bentuk kurva yang dipilih adalah bentuk persamaan parametrik interpolasi kurva Bezier orde dua (parabolik) yang didapat melalui pendekatan orde tiga (dengan empat titik bantu) (Zeid, 2005, h.224). Kurva Bezier adalah bentuk pengembangan dari algoritma de Castejeau. Persamaan interpolasi kurva Bezier orde tiga yaitu: $\mathrm{P}(\mathrm{u})=\mathrm{P}_{\mathrm{o}} \cdot(1-\mathrm{u})^{3}+3 \mathrm{P}_{1} \mathrm{u}(1-\mathrm{u})^{2}+3 \mathrm{P}_{2} \mathrm{u}^{2}(1-$

$u)+P_{3}(u)^{3} \ldots \ldots(7)$

Dimana:

$0 \leq u \leq 1$

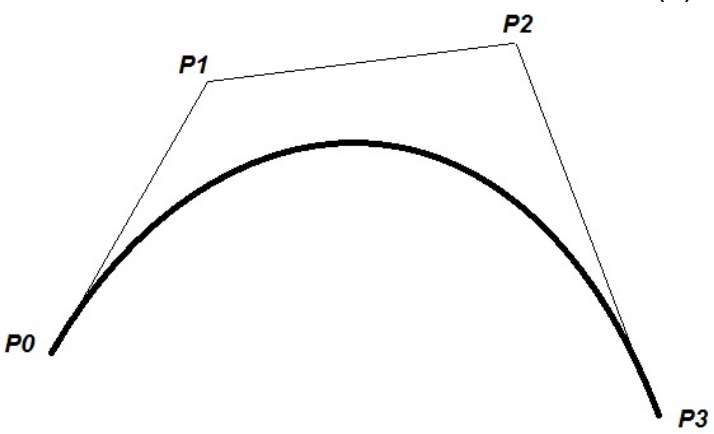

Gambar 3. Kurva Bezier Orde 3

Bentuk kurva bezier jika dikembangkan menjadi orde $\mathrm{n}$ maka konstanta berbentuk pola segitia Pascal. Berdasarkan konstanta dari segitiga Pascal dilakukan pendekatan parameter konstanta menjadi persamaan parametrik interpolasi kurva Bezier orde dua membutuhkan tiga buah titik bantu yaitu titik awal $\left(P_{0}\right)$, titik kedua $\left(P_{1}\right)$, dan titik akhir $\left(P_{2}\right)$. Persamaan Interpolasi Kurva Bezier Orde Dua:

$\mathrm{P}(\mathrm{u})=\mathrm{P}_{0} \cdot(1-\mathrm{u})^{2}+2 \mathrm{P}_{1} \mathrm{u}(1-$

$u)+P_{2}(u)^{2}$

Berdasarkan gambar interpolasi kurva Bezier orde 2 diatas maka panjang titik tengah antara P0 dan P2 adalah dua kali panjang P1 ke titik dimana u sama dengan 0,5 . 


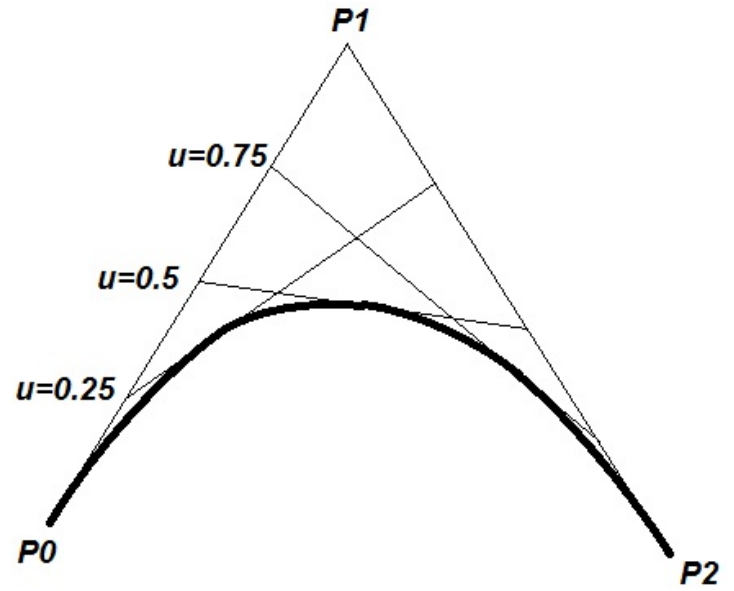

Gambar 4. Interpolasi Kurva Bezier orde 2

2.6. Hubungan (relasi) dan Struktur (Hirarki) titik obyek

Hubungan antar titik atau lingkaran yang dikembangkan merupakan pusat dari gerakkan garis-garis yang terhubung, sehingga apabila titik tersebut ditransformasikan maka akan mengubah koordinat satu titik pada dua garis yang terhubung (rigid).

Hubungan rigid antar titik dapat menggerakan titik lain atau garis lain yang berada pada hirarki di bawahnya. Misalnya seperti gerakkan lengan diangkat dari bahu maka tangan dan jari akan mengikuti.

\subsection{Petunjuk Antarmuka Pemakai}

Petunjuk antarmuka pemakai yang terintegrasi dalam proses disain aplikasi (Shneiderman, 2005, h.61-66) berisi: adanya navigasi antarmuka, pengorganisasian tampilan, membuat perhatian pemakai, fasilitas masukkan data.

a. Navigasi antarmuka

b. Pengorganisasian tampilan layar menurut Smith dan Mosier memiliki 5 tujuan yang dijadikan petunjuk yaitu: Tampilan data konsisten selama proses disain, Asimilasi informasi efisien oleh pemakai, Beban memori minimal pada pemakai, Tampilan data compatibel dengan data masukkan, Fleksibel untuk pengendalian tampilan data yang pemakai.

c. Membuat perhatian pemakai,

d. fasilitas masukkan data

\subsection{Kerangka Berpikir}

Kondisi awal, berupa fitur-fitur aplikasi Amorik2 masih berupa model rangka garis tidak menampilkan model obyek lebih nyata terlihat sebagai bidang yang menggambatkan tubuh, lengan tangan, dan kaki. Pembentukan frameframe gerakkan antara dua frame kunci menggunakan persamaan garis lurus mengakibatkan gerakkan masih kaku dan membutuhkan frame kunci yang lebih banyak untuk menghasilkan gerakkan melengkung. Dan antarmuka pemodelan karakter dan pembuatan frame kunci serta pembuatan animasi perlu dikembangkan agar memberikan navigasi, pengorganisasian tampilan, membuat perhatian pemakai, fasilitas masukkan data yang baik.

Tindakan yang akan dilakukan adalah melakukan analisa, disain dan pengembangan aplikasi agar dapat mengimplementasikan pemodelan obyek rangka berbentuk bidang melalui komponen model berbasis dua garis singgung terhadap dua lingkaran. Pembentukan gerakkan melengkung dapat dilakukan melalui tiga frame kunci menggunakan persamaa. Pembentukan gerakkan melengkung dapat dilakukan melalui tiga frame kunci menggunakan persamaan interpolasi kurva Bezier orde dua untuk menghasilkan frameframe gerakkan antara ketiga frame kunci. Pembentukan antarmuka perlu dikembangkan agar memberikan navigasi, pengorganisasian tampilan, membuat perhatian pemakai, fasilitas masukkan data yang baik.

Tujuan/hasil yang diharapkan aplikasi dapat memberikan kemudahan dalam pembuatan model karakter, mengatur posisi karakter dalam bidang kerja dan menjadikan sebagai frame kunci yang model karakter, mengatur posisi karakter dalam bidang kerja dan menjadikan sebagai frame kunci yang sesuai.

Pengguna dapat membuat animasi berdasarkan frame kunci dengan gerakkan yang luwes terutama gerakkan melengkung, Pengguna dapat menyimpan data posisi karakter, frame kunci, dan frame-frame hasil proses penggambaran antara (inbetween) frame-frame kunci. Frame-frame dalam format bitmap dapat diwarnai dan digabub Frame-frame dalam format bitmap dapat diwarnai dan digabungkan dengan gambar Latarkan dengan gambar Latar untuk dibuatkan video animasi menggunakan perangkat lunak aplikasi pembuatan video dalam format semacam mpg4, avi dan lain sebagainya.

\section{Metodologi}

Tahapan Kajian dan pengembangan aplikasi dengan metode pengembangan protoipe melalui tahapan identifikasi masalah, analisa dan perancangan, pengembangan, pengujian/ implementasi, evaluasi, pengulangan tahapan dari analisa sampai evaluasi, Hasil akhir pengembangan aplikasi selesai sampai hasil yang mencukupi kebutuhan.

Pengumpulan data sebelum pengembangan melalui kajian hasil implementasi Amorik2 dan studi pustaka konsep persamaan garis singgung pada lingkaran dan persamaan interpolasi kurva bezier serta konsep teori antarmuka pemakai. Pengumpulan data setelah pengembangan tahap pertama dari hasil uji coba implementasi aplikasi melalui pembelajaran mata kuliah Teknik Animasi tahun ajar 2014 dengan metode observasi dan evaluasi dan saran pada laporan kelompok peserta dan pada bulan kedua tahun 2015 pelatihan peserta SMP dan SMA dalam rangka Pengabdian Kepada Masyarakat dengan metode observasi dan kuesioner sebagai evaluasi progres pengembangan aplikasi tahap kedua. 


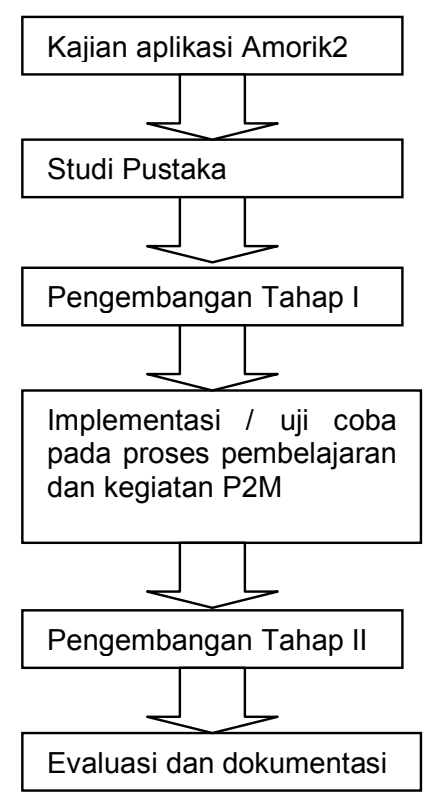

Gambar 5. Tahapan pengembangan Amorik3

Analisis dilakukan dalam beberapa tahap yaitu analisis awal berupa kajian aplikasi Amorik2, kemudian analisis kajian kepustakaan. Pada tahap pengembangan dilakukan analisis untuk disain dan pengembangan tahap I. Analisa kebutuhan untuk perancangan berupa Penerapan Pemodelan Obyek Rangka Dua Dimensi dan Interpolasi Kurva bezier orde dua, serta pembuatan antarmuka pemakai secara sistimatik dan sistemik yang memudahkan penggunaan aplikasi sehingga dapat membuat gerakkan animasi secara efektif dan efisien.

Setelah implementasi dan uji coba pada proses pembelajaran dan dilanjutkan uji coba pada kegiatan P2M. Dari hasji coba pada kegiatan P2M. Dari hasil tersebut dilakukan analisis untuk disain dan pengembangaan tahap II sehingga hasil yang didapat dibahas untuk mendapatkan kesimpulan.

Pengujian/implementasi aplikasi dilakukan dalam dua tahap yaitu oleh mahasiswa (peserta mata kuliah Tenik Animasi) sebagai pengujian tahap pertama, dilakukan sebanyak empat kelas @ 35 peserta dalam lima pertemuan @ 100 menit. Dan siswa SMA (14 peserta) dan siswa SMP (60 peserta) sebagai pengujian tahap kedua, dilakukan pada kegiatan ekstra kurikuler @ dua pertemuan. Kedua pengujian diberikan kesempatan untuk menyelesaikan tugas selama dua minggu.

Hasil implementasi aplikasi dilakukan terhadap Mahasiswa sebanyak 120 orang, Siswa SMA sebanyak 15 orang, dan Siswa SMP sebanyak 60 orang. Waktu implementasi bagi mahasiswa sebanyak 5 kali 100 menit pertemuan telah menghasilkan video animasi sebanyak 8 tim. Namun 3 tim yang membuat gerakan cukup baik.

Waktu implementasi bagi siswa SMA dan SMP masing-masing sebanyak 2 kali 90 menit pertemuan
4. Hasil dan Pembahasan

Hasil Pemodelan Obyek Rangka Dua Dimensi

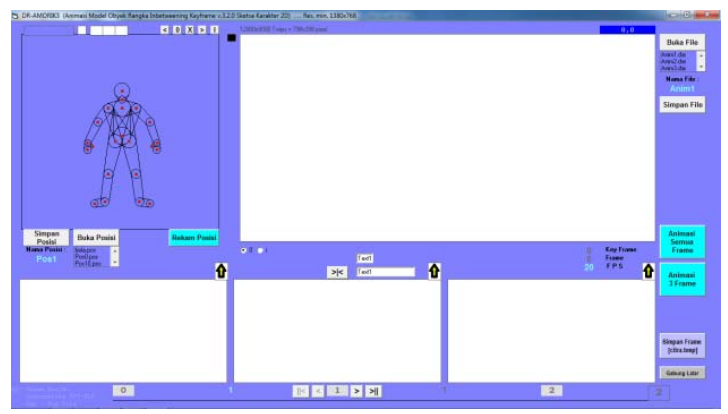

Gambar 6. Tampilan Antarmuka Pemakai Amorik3

Pemodelan Obyek Rangka Dua Dimensi berbasis dua garis singgung pada dua lingkaran menjadi elemen bidang pembentukan model manusia. Pemodelan obyek rangka dimulai dengan membentuk posisi elemen model kemudian ditempatkan bidang gambar untuk dijadikan keyframe awal. Berikutnya dengan cara yang sama yaitu mengubah posisi elemen dan menempatkan pada bidang gambar untuk dijadikan keyframe kedua dan berikutnya keyframe ketiga.

Tabel 1. perbandingan Amorik2 dan Amorik3

\begin{tabular}{|c|c|c|}
\hline Metode & Amorik2 & Amorik3 \\
\hline $\begin{array}{l}\text { Pembentuk } \\
\text { Model }\end{array}$ & $\begin{array}{l}\text { Titik sebagai } \\
\text { vertex / engsel } \\
\text { penghubung } \\
\text { garis / pusat } \\
\text { putaran garis. } \\
\text { Terdapat } 15 \text { titik } \\
\text { penghubung } \\
\text { garis }\end{array}$ & $\begin{array}{l}\text { Pusat Lingkaran } \\
\text { sebagai vertex / } \\
\text { pusat putaran garis / } \\
\text { Lingkaran } \\
\text { penghubung dua } \\
\text { garis singgung ke } \\
\text { lingkaran lain. } \\
\text { Terdapat } 21 \\
\text { lingkaran } \\
\text { penghubung dua } \\
\text { garis singgung }\end{array}$ \\
\hline Gerakkan & $\begin{array}{l}\text { Gerakan } \\
\text { dihasilkan tiap } \\
\text { titik posisi yang } \\
\text { sama dari dua } \\
\text { frame kunci } \\
\text { model. } \\
\text { Gerak antar titik } \\
\text { membentuk titik- } \\
\text { titik antara } \\
\text { (inbetween) dari } \\
\text { persamaan garis } \\
\text { lurus. }\end{array}$ & $\begin{array}{l}\text { Gerakan dihasilkan } \\
\text { tiap titik posisi } \\
\text { lingkaran yang } \\
\text { sama dari tiga frame } \\
\text { kunci model. } \\
\text { Gerak antar titik } \\
\text { lingkaran dari ketiga } \\
\text { frame kunci } \\
\text { membentuk titik-titik } \\
\text { antara (inbetween) } \\
\text { berdasarkan } \\
\text { pendekatan } \\
\text { persamaan } \\
\text { parametrik va } \\
\text { bezier kubik (orde } \\
\text { dua/parabolik). }\end{array}$ \\
\hline Antarmuka & $\begin{array}{l}\text { Terdiri dari } \\
\text { bidang pengatur } \\
\text { model, dua } \\
\text { bidang frame } \\
\text { kunci, sebuah } \\
\text { bidang gerak } \\
\text { animasi, } \\
\text { informasi peng } \\
\text { turan }\end{array}$ & $\begin{array}{l}\text { Terdiri dari bidang } \\
\text { pengatur model, tiga } \\
\text { bidang frame kunci, } \\
\text { sebuah bidang } \\
\text { gerak animasi, } \\
\text { informasi peng turan }\end{array}$ \\
\hline
\end{tabular}




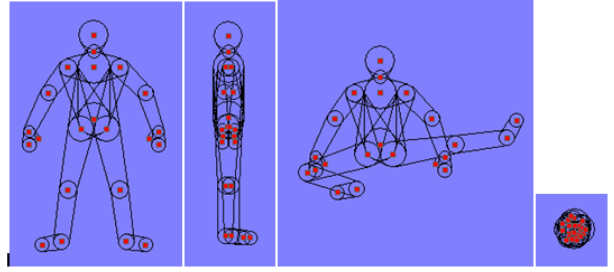

Gambar 7. Pemodelan pengaturan posisi titik

Hasil Penerapan Interpolasi Kurva bezier orde dua

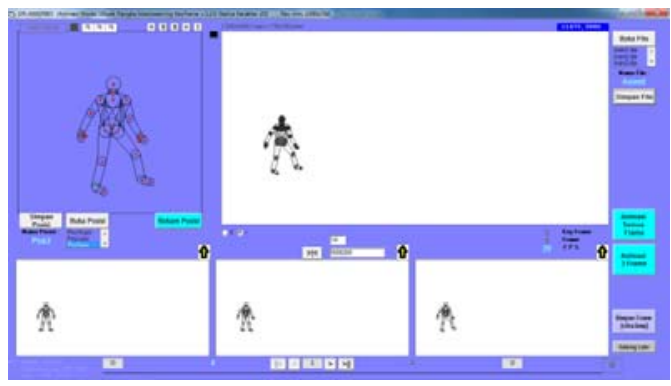

Gambar 8. Pengaturan model karakter kedalam bidang animasi dan frame kunci

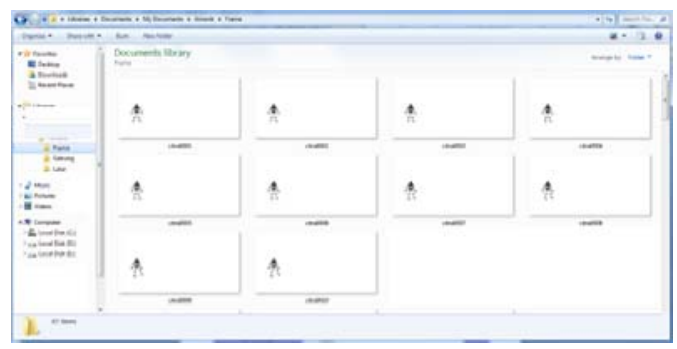

Gambar 9. Hasil perekaman frame-frame dalam format raster (bitmap)

Aplikasi yang dihasilkan dapat menunjukkan metode yang diterapkan dapat menghasilkan berbagai posisi elemen dengan bentuk model orang yang sesuai dengan bentuk yang diharapkan dari berbagai sisi. Selain model orang, model bola, model hewan mamalia (tanpa ekor) dapat dibentuk.

Penerapan Interpolasi Kurva bezier orde dua dengan menjalankan algoritma program yang menggerakan secara ilusi visual sejumlah frameframe yang terbentuk diantara (inbetweening) keyframe awal ke keyframe tengah dan ke keyframe akhir.

Hasil yang didapat menunjukkan perubahan gambar pada setiap frame secara halus mengikuti rangkaian titik-titik yang terbentuk dari persamaan parametrik interpolasi kurva bezier orde dua. Gerakkan terbaik jika ketiga keyframe menjadi posisi elemen terbaik.

Telah dapat membuat gerakkan cukup baik untuk sebagian peserta namun disebabkan keterbatasan waktu penggunaan dalam pelatihan sehingga sebagian besar peserta belum dapat mengembangkan gerakkan yang lebih baik.

\section{Kesimpulan dan Saran}

Berdasarkan pembahasan diatas disimpulkan bahwa pengembangan aplikasi Amorik dua dimensi dimodelkan dengan menerapkan metode persamaan dua garis singgung pada dua lingkaran dapat membentuk model obyek rangka dua dimensi berupa model manusia. Pengembangan model manusia terdiri dari 21 titik simpul (lingkaran) yang berelasi dengan hirarki terstruktur secara unik.

Pembuatan gambar-gambar antara dapat menghasilkan gerakkan melengkung lebih sederhana dan luwes dengan pengaturan tiga gambar kunci (keyframe) yang merupakan kumpulan tiga titik parameter persamaan interpolasi kurva bezier orde dua.

Pengaturan antarmuka sudah menerapkan navigasi berupa informasi per bagian dari kiri atas ke kanan dan kedari kiri atas ke kanan dan ke bawah, pewarnaan untuk input data secara konsisten, sehingga memberikan pengorganisasian tampilan, membuat perhatian pemakai, fasilitas masukkan data yang cukup baik.

Pewarnaan model masih secara konvensional sehingga masih membutuhkan waktu dan ketrampilan khusus. Animasi model dilakukan dengan menerapkan perubahan posisi gambar model berdasarkan interpolasi kurva bezier orde dua dapat menghasilkan gerakkan melengkung secara halus.

Saran pembuatan model animasi memerlukan pengalaman mengatur seni gerak melalui penentuan tiga gambar kunci (keyframe) dan penentuan sejumlah gambar antara yang menghasilkan kecepatan gerakan yang diinginkan.

Perlu penambahan fitur menghilangkan garisgaris dalam sehingga menampilkan obyek dengan garis tepi. Dan model agar dapat diberi warna obyek secara mudah, Transformasi skalatis dari model perlu ditambahkan baik proporsional ( $\mathrm{nx}, \mathrm{ny})$ maupun non proporsional (nx, my).

Untuk hasil terbaik membutuhkan pengalaman dan ketelitian mengamati gerakkan natural. Untuk memberi efek animasi dapat mengikuti beberapa persyaratan gerakan dari 12 prinsip Walt Disney. 


\section{Daftar Pustaka}

Chapra, Stephen C., Raymon J Canale(1990) , Metode Numerik Jakarta: Penerbit Universitas Indonesia.

Gesner, Rusty \& Joseph Smith (1992), "Maximizing AutoCAD", Carmel: New Rider Publishing.

Krishnamurthy, N, (2002), "Introduction Computer Graphics", Singapore: Mc Graw-Hill International Edition,.

Shneiderman, Ben., Catherine Plaisant (2005), "Designing The User Interface", 4th edition, Boston, Pearson Education, Inc.

Xiang, Zhigang, Roy Plastock (2001), Computer Graphics, 2nd ed., Singapore: McGraw-Hill International Edition.

Zeid, Ibrahim, Mastering CAD/CAM, Singapore: McGraw-Hill, 2005, p.201. 